University of Nebraska - Lincoln

DigitalCommons@University of Nebraska - Lincoln

Sociology Department, Faculty Publications

Sociology, Department of

February 2005

\title{
The Long Reach of Divorce: Divorce and Child Well-Being across Three Generations
}

Paul R. Amato

Pennsylvania State University

Jacob Cheadle

University of Nebraska-Lincoln, jcheadle2@unl.edu

Follow this and additional works at: https://digitalcommons.unl.edu/sociologyfacpub

Part of the Sociology Commons

Amato, Paul R. and Cheadle, Jacob, "The Long Reach of Divorce: Divorce and Child Well-Being across Three Generations" (2005). Sociology Department, Faculty Publications. 25.

https://digitalcommons.unl.edu/sociologyfacpub/25

This Article is brought to you for free and open access by the Sociology, Department of at DigitalCommons@University of Nebraska - Lincoln. It has been accepted for inclusion in Sociology Department, Faculty Publications by an authorized administrator of DigitalCommons@University of Nebraska - Lincoln. 


\title{
The Long Reach of Divorce: Divorce and Child Well-Being across Three Generations
}

\author{
Paul R. Amato and Jacob Cheadle
}

Department of Sociology, The Pennsylvania State University, 201 Oswald Tower, University Park, PA 16802-6207

\begin{abstract}
We used data from the study of Marital Instability Over the Life Course to examine links between divorce in the grandparent generation and outcomes in the grandchild generation $(N=691)$. Divorce in the first generation (G1) was associated with lower education, more marital discord, weaker ties with mothers, and weaker ties with fathers in the third generation (G3). These associations were mediated by family characteristics in the middle generation (G2), including lower education, more marital discord, more divorce, and greater tension in early parent-child relationships. In supplementary analyses, we found no evidence that the estimated effects of divorce differed by offspring gender or became weaker over time. Our results suggest that divorce has consequences for subsequent generations, including individuals who were not yet born at the time of the original divorce.
\end{abstract}

Keywords: divorce, intergenerational transmission, life course, marital conflict, parent-child relationships

Experiencing parental divorce as a child appears to increase the risk of a variety of problems in adulthood. Compared with adults with continuously married parents, adults with divorced parents tend to obtain less education, earn less income, have more troubled marriages, have weaker ties with parents, and report more symptoms of psychological distress. Marital disruption is not uniformly harmful to children, and most offspring with divorced parents develop into well-adjusted adults. Nevertheless, the increase in risk associated with parental divorce is not trivial, and for some outcomes (such as poor father-child relationships), the estimated effects of parental divorce are quite strong (see Amato, 2000, for a review).

Although marital instability in one generation is linked with problems in the next generation, few studies have considered the extent to which these linkages may extend across more than two generations. It is well known that some family characteristics, such as poverty, can persist across multiple generations. Similarly, the consequences of marital instability may ripple through the lives of former spouses' descendants, touching family members who were not yet born when the original divorce occurred. Our study explores this general hypothesis. We use a 20-year longitudinal study to (a) examine associations between grandparents' divorce and a variety of outcomes for grandchildren, and (b) determine the factors that mediate these associations. We also use these data to examine two related issues: whether the estimated long-term effects of parental divorce differ for sons and daughters, and whether these estimated effects have become weaker (or stronger) over time.

\section{Conceptual framework}

Our research is based on a life course perspective, which assumes that events and circumstances in one generation can have long- 
term consequences for subsequent generations (Bengtson \& Allen, 1994; Elder, 1994). The specific model that guides our research appears in Figure 1. Our model assumes that G1 divorce has the potential to affect a variety of G3 outcomes, including educational attainment, marital discord, divorce, the quality of relationships with mothers and fathers, and psychological well-being. We assume that most of these effects are mediated by socioeconomic attainment and family processes in the middle (G2) generation. Although most of the putative effects of G1 divorce are indirect, our model allows for the possibility that $\mathrm{G} 1$ divorce has direct effects on G3 outcomes, controlling for G2 variables.

\section{Intergenerational consequences of divorce}

Socioeconomic attainment. Compared with offspring with two continuously married parents, offspring with divorced parents are more likely to drop out of high school, less likely to attend college, more likely to be unemployed, and more likely to experience economic hardship as adults (Amato \& Keith, 1991; McLanahan \& Sandefur, 1994). Marital disruption appears to affect these outcomes for several reasons. Divorce is typically followed by a decline in the standard of living of children and their custodial parents, usually mothers (Teachman \& Paasch, 1994). This decline occurs because households lose economies of scale, mothers earn less income than fathers, and fathers often fail to pay child support. Economic adversity makes it difficult for parents to provide resources to children (such as books, computers, travel, private tutors, and assistance with college expenses) that facilitate children's educational success. In addition, divorce is often accompanied by a variety of stressful events and circumstances, such as continuing discord between parents, moving to new neighborhoods, changing schools, parental remarriage, and additional parental divorces (Amato, 2000). Exposure to these stressors can disrupt children's efforts to learn and do well in school.

Parent-child relationships. Parental divorce is associated with weak emotional bonds between parents and children in adulthood (Zill, Morrison, \& Coiro, 1993). Longitudinal studies have suggested that marital discord erodes children's ties with both parents, irrespective of whether the marriage eventually ends in divorce (Amato \& Booth, 1996). In

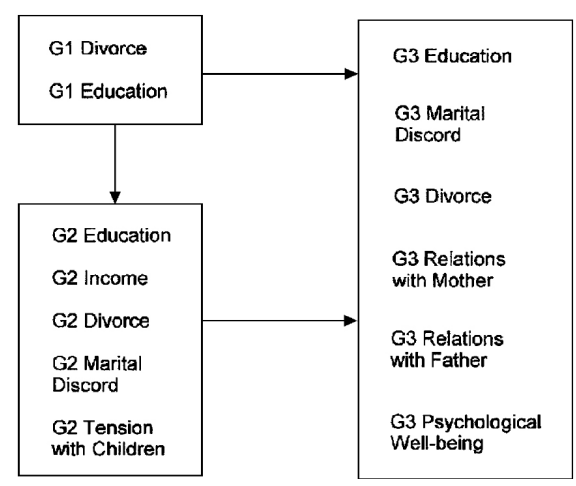

Figure 1. Conceptual Model Linking Generation 1 (G1) Divorce With Generation 2 (G2) Mediators and Generation 3 (G3) Outcomes.

addition, following divorce, a variety of stressful circumstances (economic hardship, living in poor neighborhoods, lack of social support) can disrupt the quality of mother-child interaction. Studies have revealed that divorced single mothers, compared with continuously married mothers, tend to show less warmth toward their children, engage in harsher punishment, and monitor their children less effectively (Hetherington \& Clingempeel, 1992). With respect to fathers, postdivorce visitation arrangements make it difficult for noncustodial fathers to maintain close ties with their children. As a result, many fathers visit their children infrequently and gradually disengage from their children's lives (Lamb, 1999).

Marital quality and stability. Research has consistently suggested that marital discord and divorce are transmitted across generations. Compared with spouses with continuously married parents, spouses with divorced parents tend to report less marital satisfaction (Ross \& Mirowsky, 1999), engage in more conflict (Tallman, Gray, Kullberg, \& Henderson, 1999), and think about divorce more often (Webster, Orbuch, \& House, 1995). Similarly, parental divorce is associated with a greater likelihood of seeing one's own marriage end in divorce (Bumpass, Martin, \& Sweet, 1991; Wolfinger, 1999).

Several processes may account for the transmission of marital problems across generations. A social learning perspective suggests that children acquire a variety of interpersonal skills through the observation of adult models (Ban- 
dura, 1973; O'Leary \& Cascardi, 1998). Spouses who later divorce (compared with spouses who remain married) listen to their partners less attentively, express more negative emotion in marital conversations, are more critical of their partners, are more likely to respond to criticism defensively, avoid or withdraw from problemsolving discussions, and report more problems with jealousy, moodiness, and controlling anger (Gottman, 1994; Leonard \& Roberts, 1998). Presumably, children with maritally distressed parents are less likely than other children to observe and learn positive behaviors that facilitate long-term bonds with others. These children may reach adulthood with poorly developed relationship skills and a repertoire of interpersonal behaviors that undermine marital satisfaction and stability.

Attachment theory suggests that marital discord and divorce affect children primarily by disrupting bonds with parents. According to this perspective, parent-child relationships form the basis of children's internal working models of close relationships (Hazan \& Shaver, 1992). Children with warm and supportive parents generally feel emotionally secure, view relationships positively, trust people, and are comfortable depending on others. In contrast, children with emotionally distant or hostile parents often feel emotionally insecure, find it difficult to trust people, and are uncomfortable depending on others (Davies \& Cummings, 1994). To the extent that divorce disrupts parent-child relationships, children may develop into emotionally insecure adults who engage in behaviors (such as avoiding commitment or clinging jealously to partners) that undermine long-term intimate ties.

Psychological well-being. Studies indicate that offspring with divorced parents have an elevated risk of experiencing emotional distress in adulthood (Amato \& Sobolewski, 2001; Cherlin, Chase-Lansdale, \& McRae, 1998). Education, economic security, strong relationships with parents, marital happiness, and marital stability promote mental health and a sense of well-being (Ross \& Mirowsky, 1999). To the extent that marital discord and divorce undermine these protective factors (as described earlier), offspring are likely to enter adulthood with a predisposition to experience emotional distress and general dissatisfaction with life.

\section{Extension to three generations}

If parental divorce increases the likelihood of marital discord, divorce, and other problems in the second generation, then these same risks are likely to be passed on to the third generation. These linkages across generations occur because the effects of divorce and other family problems in one generation become the causes of similar problems in the next generation. For example, if G1 divorce increases the likelihood of G2 marital discord and divorce, then G2 marital discord and divorce should increase the likelihood of G3 marital discord and divorce. Because the same causal processes are at work, family problems may be "handed down" from generation to generation.

Although the tendency for marital discord and divorce to run in families has been demonstrated repeatedly, the extent to which this process continues for more than two generations is largely unknown. Among the few studies on this topic, most have relied on cross-sectional data from a single generation. For example, Doumas, Margolin, and John (1994) found that G1 marital aggression predicted G2 marital aggression, and that G2 marital aggression in turn predicted G3 children's aggression. This study, however, was based on G2 respondents' $(n=$ 181) reports of aggression in their families of origin, and G2 respondents' ratings of their children's aggression. Individuals in violent marriages may be primed to recall parents' and children's aggressive behavior, however, irrespective of the actual levels of G1 and G3 aggression. Because the data came from a single source, common method variance may have inflated the correlations between variables.

Caspi and Elder (1988) conducted one of the few studies that examined linkages across three generations with longitudinal data from multiple respondents. Using the Berkeley Guidance Study (collected between 1930 and 1972), they found that G1 marital conflict was associated with an elevated number of behavior problems among G2 children. Later, as adults, these G2 individuals exhibited a problematic interpersonal style that negatively affected the quality of their own marriages and the quality of their interactions with children. As in the previous generation, G3 offspring who grew up in discordant homes revealed behavioral and interpersonal problems as adults. 
These findings suggest that distressed marital relationships are passed on from one generation to the next, with problematic socialization in the family of origin serving as the causal mechanism. Although intriguing, these findings were based on a relatively small sample $(N=182)$, included women only, and were presented in a book chapter format (with minimal details on the analysis). Additional research on the transmission of marital problems across multiple generations using larger samples and more recently collected data is clearly warranted.

Our discussion thus far has assumed that the associations between parental divorce and offspring outcomes are causal rather than spurious. An alternative explanation focuses on the transmission of genetically inherited personality traits from parents to children. The discovery that the propensity for divorce is higher among monozygotic than dizygotic twins lends credence to the notion that genes predispose people to engage in behaviors that increase the risk of marital disruption (Jockin, McGue, \& Lykken, 1996; McGue \& Lykken, 1992). These inherited personality traits could reflect a tendency to engage in hostile or antisocial behavior, or difficulties in forming close emotional attachments to others. To the extent that parents' and children's personalities are correlated, parents and children may experience similar levels of marital quality, stability, and personal well-being.

With regard to possible genetic influence, one study found that the association between parental divorce and child problems was similar for adopted and biological children (Brodzinsky, Hitt, \& Smith, 1993)-a finding that cannot be explained by genetic transmission. Another study based on a large sample of twins (Kendler, Neale, Kessler, Heath, \& Eaves, 1992) found that parental divorce predicted offspring depression in adulthood, with genetic resemblance controlled statistically. These studies suggest that even if genetically inherited traits predispose children to certain emotional and behavioral problems, divorce brings about new conditions that may exacerbate these problems or create new ones. Although it has little empirical support, the genetic explanation represents an alternative perspective to the socialization explanation, and we give this view some attention in the discussion section.

\section{Goals of the current study}

We used a unique 20-year longitudinal study to examine the transmission of divorce and other family problems across three generations. Our study had two primary goals. The first was to see whether G1 divorce was associated with a range of G3 outcomes, including education, marital discord, divorce, the quality of relationships with parents, and psychological well-being. We addressed this goal by regressing G3 outcomes on G1 divorce, controlling for G1 education. Controlling for G1 education was necessary because low education could be a cause of G1 divorce and problems in subsequent generations. In preliminary analyses, we also included G3 gender, race, and age as control variables. Although these variables were associated with several G3 outcomes, they were uncorrelated with G1 and G2 variables, and hence had no effect on parameter estimates. We excluded these control variables from subsequent models for the sake of parsimony. In the analysis of G3 marital discord and divorce, however, we also included age at marriage and marital duration because these variables have changed over time and are usually correlated with divorce. For the same reason, we included age at marriage in the equation for predicting offspring's marital discord.

Our second goal was to see whether G1 $\rightarrow$ G3 associations were mediated by socioeconomic variables and family processes in the middle (G2) generation. To accomplish this goal, we added a variety of $G 2$ variables to the statistical models, including parents' education, family income, tension in early parent-child relationships, marital discord, and divorce. Declines in the strength of G1 $\rightarrow$ G3 associations between the first model (without G2 variables) and the second model (with G2 variables) provided evidence of mediation.

Our study also had two secondary goals. First, some evidence suggests that the long-term consequences of family processes (including marital discord and divorce) may be stronger for daughters than sons. Research has suggested that women are more sensitive than men to relationship dynamics (Thompson \& Walker, 1991). Caspi and Elder (1988) argued that intergenerational influence is stronger for women than men, largely because women's life courses are more constrained by family circumstances. Consistent with these views, a meta-analysis 
(Amato \& Keith, 1991) found that the estimated effects of parental divorce on offspring's educational attainment were significantly stronger for daughters than sons. Similarly, Amato and Booth (1997) found that associations between family-of-origin characteristics and offspring outcomes were statistically significant more often for daughters than sons. Based on this prior work, we tested the hypothesis that the transmission of family problems across generations is more common among women than men.

Second, we considered the hypothesis that the effects of divorce have become weaker in recent decades. Amato and Keith (1991), in a meta-analysis of studies conducted in the 1960s through the 1980s, found that the associations between parental divorce and offspring's educational attainment were weaker in more recent studies than in earlier studies. Similarly, Wolfinger (1999), using data from the General Social Survey, found that the intergenerational transmission of divorce became less pronounced between 1973 and 1996. Wolfinger attributed this change to a decline in the social stigma associated with divorce. Given the small number of studies on this topic, we addressed this issue by comparing the magnitude of the associations between parental divorce and offspring outcomes across 10-year birth cohorts, beginning with the 1920s and finishing with the 1970s.

\section{Method}

\section{Sample}

Procedure. Our analysis was based on a 20year longitudinal study of Marital Instability Over the Life Course (Booth, Amato, \& Johnson, 2001). The target population consisted of all married individuals in households in the contiguous United States with a telephone, both spouses present, and both spouses 55 years of age or less in 1980. Telephone interviewers used random digit dialing to select a sample of households, and a second random procedure to select either the husband or wife. Seventeen percent of targeted individuals could not be reached after 20 call-backs. Of those individuals contacted, $78 \%$ gave complete interviews. The final sample consisted of 2,033 married persons (not couples). When compared with U.S. Census data, the sample was representative of married individuals with respect to age, race, household size, home ownership, presence of children, and region of the country. The sample was contacted again in 1983, 1988, and 1992, with reinterview rates of $78 \%, 66 \%$, and $58 \%$, respectively.

Adult offspring (19 years of age or older) of the primary respondents were interviewed in 1992, 1997, and 2000. Eighty-seven percent of parents with eligible children provided names and telephone numbers, and we interviewed $88 \%$ of these individuals, for an overall completion rate of $77 \%$. When parents had more than one eligible child, we used a random procedure to select the child for inclusion in the study. Offspring who were interviewed for the first time in 1992 were reinterviewed in 1997 and 2000, and offspring interviewed for the first time in 1997 were reinterviewed in 2000. A total of 691 adult offspring were interviewed on at least one occasion.

In 1980, the primary respondents (the G2 generation) provided information on whether their parents or their spouses' parents (the G1 generation) had divorced. Primary respondents also provided information on their parents' and their spouses' parents' levels of education. The 1980, 1983, 1988, and 1992 interviews provided information on G2 education, G2 income, G2 marital discord, G2 divorce, and G2 tension with children. The 1992, 1997, and 2000 interviews with offspring (the G3 generation) provided information on G3 education, G3 marital discord, G3 divorce, G3 relationships with parents, and G3 psychological well-being.

Sample characteristics. With respect to the G3 sample, about half (51\%) were women, the majority were White $(92 \%)$, and about half $(52 \%)$ had children. In 2000 , the median age was 32 and the median duration of marriage (for those currently married) was 7 years.

\section{Independent (G1) variables}

Two G1 characteristics served as independent variables: divorce and education. Divorce was a dichotomous variable that indicated whether a divorce occurred in the first generation $(1=$ divorce, $0=$ no divorce $)$. Because G3 respondents have two sets of grandparents, we counted divorces among either the paternal or maternal grandparents. Of these 691 respondents, $10 \%$ had divorced paternal grandparents only, $11 \%$ had divorced maternal grandparents only, and $3 \%$ had divorced paternal and maternal grandparents. G1 education was the 
mean years of education of the main respondent's (G2) parents and the main respondent's spouse's parents.

\section{Dependent (G3) variables}

Education. Education was coded as the individual's years of education.

Marital discord. G3 marital discord was based on three short scales. Five items assessed the level of conflict in the marriage: arguments over the household division of labor, arguments over the children, the frequency of disagreement in general, the number of serious quarrels in the past 2 months, and whether violence initiated by either spouse had occurred in the marriage $(\alpha=.65)$. The second scale assessed 14 marital problems, including whether respondents or their spouses get angry easily, have feelings that are easily hurt, are jealous, are domineering, are critical, avoid talking, or have had extramarital sexual relationships. The total number of problems served as the scale score $(\alpha=.72)$. The third scale assessed divorceproneness, which includes a cognitive component (thinking that one's marriage is in trouble, thinking about divorce) and a behavioral component (talking with friends or family members about divorce, talking with one's spouse about divorce). This 13-item scale had an alpha coefficient of .91. G3 respondents completed the measures of marital discord either in 1992 or 1997, depending on when they entered the study and when they married. For G3 respondents who were married in 1992 and 1997, we took the mean of their scores in the two survey years. To create a summary measure of marital discord, we used the first component of a principal components analysis, which accounted for $71 \%$ of the variance in the three scales. Factor loadings were .83 or higher. This variable was available for 326 G3 respondents married at the time of one of the interviews.

Divorce. A total of $450 \mathrm{G} 3$ respondents had married by 2000. G3 divorce is a dichotomous variable that indicates whether a divorce occurred among these respondents by the time of the final survey $(1=$ divorce, $0=$ no divorce $)$. Of ever-married respondents, 108 had divorced by 2000 .

Relations with parents. G3 respondents rated their parents on five items, including
"How well do you feel that your mother understands you?" and "How much respect does your father show you?" ( 1 = not very much, 2 $=$ somewhat, $3=$ a great deal). Other items dealt with trust, fairness, and the overall closeness of the relationship. Five parallel items assessed the mother-child relationship. Reliability coefficients were .87 for mothers and .90 for fathers.

Psychological well-being. We used four scales to measure G3 psychological well-being: the Rosenberg (1965) measure of self-esteem $(\alpha$ $=.77$ ); the Langner (1962) measure of distress symptoms $(\alpha=.73)$; a seven-item scale of satisfaction with various domains of life, including job, home, friends, and neighborhood $(\alpha=.65)$; and a single-item rating of overall happiness with life $(1=$ not very happy, 2 = pretty happy, 3 $=$ very happy). The mean correlation between the four measures was .36 $(p<.001)$. Respondents completed these scales either in 1992 or in 1997. For individuals interviewed on more than one occasion, we took the mean of their scores in the two survey years. To create a summary measure, we relied on the first component of a principal components analysis, which captured $52 \%$ of the total variance across the four scales. Loadings ranged from .67 (self-esteem) to .74 (happiness).

\section{Mediating (G2) variables}

Socioeconomic status. We assessed G2 socioeconomic status with two variables. The first was the mean years of education of the G2 respondent and the G2 respondent's spouse. The second was the total G2 family income, in thousands of dollars. Income was translated into 1992 dollars and averaged across the 1980, 1983, 1988, and 1992 waves of data.

Marital discord. G2 respondents completed the same three measures of marital discord (conflict, problems, and divorce-proneness) described earlier. (Reliability coefficients were comparable with those described earlier.) These measures were administered in 1980, 1983, 1988, and 1992. For respondents who remained continuously married during this period, we calculated the mean score across all four waves to provide a general estimate of discord during this 12-year period. For respondents who divorced during the study, we took the mean of all scores prior to marital dissolution. For example, for respondents who di- 
vorced in 1985, marital discord was the mean of the scores in 1980 and 1983.

Divorce. G2 divorce was a dichotomous variable indicating whether the parents of the G3 respondents had ended their marriage in divorce $(1=$ divorce, $0=$ no divorce $)$.

Parent-child tension. This variable reflected tension in G2 parents' relationships with their children while they were growing up. In 1980, 1983, and 1988, G2 parents responded to six questions about their children, including, "Have your children given you more than the usual number of problems?" (1 =yes, $0=n o)$, "How often do you wish that you lived apart from your children?" $(1=$ never, 4 = most of the time), and "Overall, how close do you feel to your children?" $(1=$ very close, $4=$ not very close). To form a general measure of parent-child tension, we equally weighted and averaged the items across the three time periods $(\alpha=.65)$. Note that this variable refers to relations between the interviewed G2 parent and all children in the household. Information about parents' relations with the G3 focal child would have been preferable, but these data were not available. G3 children, on average, were 10 years old in 1980 and 18 years old in 1988 .

\section{Data analysis}

Data files. The analysis was based on two data files. The first file treated families as the unit of analysis, with each G1-G2-G3 set representing a single case $(n=691)$. We used this data file to study G3 education, divorce, parent-child relationships, and psychological wellbeing. The same file provided data on G3 marital discord, except that the sample size was 326 married offspring. We constructed the second data file specifically to study G3 divorce. Because divorce is a time-varying, binary variable, ever-married G3 respondents were represented in the second file with a row of data for each year they were married $(n=3,598$ person years). Cases were censored if they divorced, if their spouses died, or if they dropped out of the panel. Individuals who remained married through the final interview in 2000 were censored in that year.

Missing data. In a longitudinal study, the potential for missing data to influence the results is considerable. The most common method for dealing with missing data-casewise deletion - reduces statistical power and biases parameter estimates. To make the best use of our data, we employed full information, maximum likelihood estimation for the main analysis (Arbuckle, 1997). When using the person-year file to model G3 divorce, we employed sequential regression multiple imputation with five replications (Raghunathan, Solenberger, \& Van Hoewyk, 2002; Rubin, 1987). For further information on these methods for handling missing data, we refer the reader to Allison (2002).

Analysis. We carried out the analyses in two steps. First, we regressed the G3 outcomes (education, marital discord, divorce, relationships with parents, and psychological well-being) on G1 divorce and education. This step revealed whether G1 divorce was related to G3 outcomes, controlling for G1 education. On the second step, we added G2 variables (education, income, parent-child tension, marital discord, and divorce) to the model. This step revealed the extent to which $\mathrm{G} 2$ variables mediated the links between G1 divorce and G3 outcomes. For all ordered dependent variables, we relied on Analysis of Moment Structures (AMOS) software (Arbuckle, 1999). Although we did not adopt a latent variable approach, this software made it possible to use full information maximum likelihood estimation for missing data and to employ multigroup models to assess gender and generational differences. We relied on discrete-time event history methods, estimated with logistic regression, for analyzing G3 divorce (Allison, 1984).

Attrition. We relied on Heckman's (1979) method to correct for attrition bias in the sample. We used a probit regression equation to model the attrition of G2 parents from the panel. G3 attrition was significantly greater among African Americans, younger respondents, men, renters, respondents with a low level of education, recently married respondents, and respondents living in the South. On the basis of these significant predictors, we calculated lambda-the probability of dropping out of the panel-for each case. Lambda served as a control variable in all preliminary analyses. Adjusting for attrition bias, however, had no substantive implications for our findings. Consequently, for the sake of parsimony, we omitted this variable from the final analyses described below. 
Table 1. Correlations, Means, and Standard Deviations for Main Variables

\begin{tabular}{|c|c|c|c|c|c|c|c|c|c|c|c|c|c|}
\hline & 1. & 2. & 3. & 4. & 5. & 6. & 7. & 8. & 9. & 10. & 11. & 12. & 13. \\
\hline 1. G1 Education & 1.00 & & & & & & & & & & & & \\
\hline 2. G1 Divorce & -.02 & 1.00 & & & & & & & & & & & \\
\hline 3. G2 Education & .44 & -.10 & 1.00 & & & & & & & & & & \\
\hline 4. G2 Family income & .20 & -.03 & .43 & 1.00 & & & & & & & & & \\
\hline 5. G2 Divorce & .05 & .13 & -.04 & -.04 & 1.00 & & & & & & & & \\
\hline 6. G2 Marital discord & .02 & .20 & .01 & -.06 & .34 & 1.00 & & & & & & & \\
\hline 7. G2 Parent-child tension & -.01 & .06 & .00 & -.01 & .07 & .21 & 1.00 & & & & & & \\
\hline 8. G3 Education & .12 & -.13 & .29 & .30 & -.08 & -.07 & -.14 & 1.00 & & & & & \\
\hline 9. G3 Marital discord & .02 & .15 & -.01 & -.03 & .12 & .18 & .19 & -.06 & 1.00 & & & & \\
\hline 10. G3 Divorce & -.04 & .02 & -.11 & .00 & .10 & -.04 & .05 & -.13 & .18 & 1.00 & & & \\
\hline 11. G3 Relations mother & .00 & -.09 & .05 & .06 & -.12 & -.18 & -.14 & .10 & -.06 & -.08 & 1.00 & & \\
\hline 12. G3 Relations father & -.03 & -.09 & .05 & .07 & -.46 & -.30 & -.14 & .08 & -.19 & -.04 & .41 & 1.00 & \\
\hline 13. G3 Well-being & .01 & .01 & .02 & .04 & -.08 & -.12 & -.14 & .12 & -.40 & -.05 & .31 & .28 & 1.00 \\
\hline M & 10.65 & 0.25 & 13.49 & 54.94 & 0.21 & 0.00 & 0.00 & 14.51 & 0.00 & 0.23 & 0.00 & 0.00 & 0.00 \\
\hline SD & 2.59 & 0.43 & 2.19 & 18.99 & 0.38 & 1.00 & 1.00 & 2.40 & 1.00 & 0.42 & 1.00 & 1.00 & 1.00 \\
\hline
\end{tabular}

Note: For G3 divorce and G3 marital discord, $N=450$. For all other variables, $N=691$. For G3 divorce and G3 marital discord, correlations $\geq .10$ or $\leq-.10$ are significant at $p \leq .05$ (two-tailed). For all other variables, correlations $\geq .08$ or $\leq-.08$ are significant at $p<.05$ (two-tailed).

\section{Results}

\section{Descriptives}

Descriptive statistics for all variables appear in Table 1: With respect to the means, educational attainment increased across the three generations, with the mean number of years of education rising from 10.6 (G1) to 13.5 (G2) to 14.5 (G3). One fourth (25\%) of G3 respondents had divorced grandparents. Because G3 respondents had two sets of grandparents, the rate of divorce in the first generation was lower than this figure suggests. Although not shown in the table, $13 \%$ of maternal grandparents and $13 \%$ of paternal grandparents ended their marriages in divorce. In the middle generation, $21 \%$ of marriages ended in divorce. Almost one fourth $(23 \%)$ of G3 marriages had ended in divorce by 2000. Given that the median duration of marriage for this group was 7 years, and given that about half of all divorces occur within the first 7 years of marriage, the eventual rate of divorce in the third generation is likely to be double this figure. With the exception of education, income, and divorce, the unit of measurement for the remaining variables was arbitrary, so we standardized these distributions to have means of 0 and standard deviations of 1 to facilitate interpretation.

Although not shown in the table, the median year of divorce was 1958 in the first generation,
1987 in the second generation, and 1996 in the third generation. The median year of birth in the third generation was 1968 (not shown). Consequently, only a few G3 respondents $(7 \%)$ had been born when their grandparents divorced.

The correlation matrix reveals several noteworthy findings. Consistent with prior studies, G1 divorce was negatively associated with G2 education, positively associated with G2 divorce, and positively associated with G2 marital discord. The correlation between G1 divorce and G2 parent-child tension was in the expected direction, but only approached significance $(p<.1)$. These correlations appear to be modest, but this reflects the fact that G1 divorce was a skewed dichotomous variable. Measures of effect size provide better estimates of the strength of these associations. Although not shown in the table, G1 divorce was associated with an increase in G2 marital discord equivalent to .48 of a standard deviation, and with a decline in G2 education equivalent to .19 of a standard deviation (.41 years). In addition, G1 divorce doubled the odds of G2 divorce (odds ratio $=1.98$ ). These associations are large enough to be nontrivial.

Consistent with the assumption that divorce has implications that extend beyond two generations, G1 divorce was negatively associated with G3 education, positively associated with G3 marital discord, and negatively associ- 
Table 2. G1 and G2 Predictors of G3 Education, Marital Discord, and Divorce

\begin{tabular}{|c|c|c|c|c|c|c|}
\hline \multirow[b]{2}{*}{ Predictor } & \multicolumn{2}{|c|}{ G3 Education } & \multicolumn{2}{|c|}{ G3 Marital Discord } & \multicolumn{2}{|c|}{ G3 Divorce } \\
\hline & Model 1 & Model 2 & Model 1 & Model 2 & Model 1 & Model 2 \\
\hline G1 Divorce & $-0.74^{* *}$ & $-0.54^{* *}$ & $0.35^{* *}$ & 0.21 & 0.09 & -0.06 \\
\hline G1 Education & $0.11^{* * *}$ & -0.01 & 0.01 & 0.00 & 0.01 & 0.01 \\
\hline G2 Divorce & & $-0.26 \dagger$ & & 0.16 & & $0.80^{* * *}$ \\
\hline G2 Education & & $0.22^{* * *}$ & & 0.00 & & -0.05 \\
\hline G2 Income & & $0.03^{* * *}$ & & 0.00 & & 0.05 \\
\hline G2 Marital discord & & 0.01 & & $0.12 \dagger$ & & -0.04 \\
\hline G2 Parent-child tension & & $-0.30^{* * *}$ & & $0.15^{* *}$ & & -0.03 \\
\hline G3 Age at marriage & & & & -0.01 & & $-0.14^{* * *}$ \\
\hline G3 Marital duration & & & 0.06 & 0.06 & $0.23^{*}$ & $0.23^{*}$ \\
\hline G3 Marital duration ${ }^{2}$ & & & -0.01 & -0.01 & $-0.02^{* *}$ & $-0.02^{* *}$ \\
\hline $\mathrm{R}^{2} / \mathrm{X}^{2}$ & $.03^{* *}$ & $.15^{* * *}$ & $.04^{*}$ & $.09^{* *}$ & $9.88^{*}$ & $42.75^{* * *}$ \\
\hline
\end{tabular}

Note: $N=691$ for G3 education, 326 for G3 marital discord, and 3,598 person years for G3 divorce. Table values for G3 education and G3 marital discord are unstandardized regression coefficients based on maximum likelihood estimation. Table values for G3 divorce are logit coefficients. Significance tests are two-tailed.

$\dagger p<.10 .{ }^{*} p<.05 .{ }^{* *} p<.01 .{ }^{* * *} p<.001$.

ated with the quality of G3 relations with mothers and fathers. These correlations demonstrate that divorce in the grandparent generation was linked with several problematic outcomes in the grandchild generation. We address the issue of effect sizes in subsequent analyses.

\section{Multivariate analysis}

Table 2 presents maximum likelihood estimates of the associations between G1 divorce and G3 education, controlling for G1 education. In Model 1, G1 divorce was associated with lower G3 educational attainment (.74 of a year). This association is equivalent to an effect size of .31 of a standard deviation. G1 education also predicted G3 education, with each year of G1 education increasing G3 education by .11 of a year. Model 2 reveals that G3 education was negatively associated with G2 divorce at a level that approached significance $(p=.06)$, and positively associated with G2 education and income. Moreover, when G2 parents described their relationships with children as involving greater tension, G3 education tended to be lower.

Adding these variables to the equation reduced the association between G1 divorce and G3 education from .74 to .54 (a decline of $27 \%$ ), which suggests that G2 variables mediated slightly more than one fourth of the esti- mated effect of G1 divorce. With G2 variables in the equation, however, the coefficient for G1 divorce continued to be significant. In additional analyses (not shown), we entered the G2 variables into the equation individually (rather than in a block) to determine which variables were primarily responsible for mediating the G1 $\rightarrow$ G3 association. The variable with the strongest mediating role was G2 education. Adding this variable to the equation reduced the $\mathrm{b}$ coefficient for G1 divorce by about $20 \%$.

G1 divorce was positively associated with G3 marital discord in Model 1. Because marital discord was standardized, G1 divorce was associated with an increase in marital discord equivalent to slightly more than one third (.35) of a standard deviation. In Model 2, G2 tension with children appeared to increase G3 marital discord. In addition, the association between G2 marital discord and G3 marital discord approached significance $(p<.07)$. With all G2 variables in the equation, the estimated effect of G1 divorce declined to .21 and was no longer significant, suggesting that G2 variables mediated about one third of this association. G2 parentchild tension, and to a lesser extent, G2 marital discord, was responsible for most of the mediation. Neither age at marriage nor duration of marriage was related significantly to marital discord. 
Table 3. G1 and G2 Predictors of G3 Relations with Mother, Relations With Father, and Psychological Well-Being.

\begin{tabular}{|c|c|c|c|c|c|c|}
\hline \multirow[b]{2}{*}{ Predictor } & \multicolumn{2}{|c|}{ G3 Relations Mother } & \multicolumn{2}{|c|}{ G3 Relations Father } & \multicolumn{2}{|c|}{ G3 Well-Being } \\
\hline & Model 1 & Model 2 & Model 1 & Model 2 & Model 1 & Model 2 \\
\hline G1 Divorce & $-0.21^{*}$ & -0.12 & $-0.23^{*}$ & -0.01 & 0.02 & 0.10 \\
\hline G1 Education & 0.01 & -0.01 & 0.00 & -0.01 & 0.00 & -0.01 \\
\hline G2 Divorce & & -0.12 & & $-0.98^{* * *}$ & & -0.12 \\
\hline G2 Education & & 0.01 & & 0.01 & & 0.00 \\
\hline G2 Income & & 0.00 & & 0.00 & & 0.00 \\
\hline G2 Marital discord & & $-0.13^{* *}$ & & $-0.15^{\star *}$ & & $-0.10^{*}$ \\
\hline G2 Parent-child tension & & $-0.11^{* *}$ & & $-0.09^{*}$ & & $-0.12^{* *}$ \\
\hline$R^{2}$ & $.01^{*}$ & $0.05^{*}$ & $.01^{*}$ & $0.25^{* * *}$ & .00 & $0.03^{*}$ \\
\hline
\end{tabular}

Note: $N=691$. Table values are unstandardized regression coefficients based on maximum likelihood estimation. Significance tests are two-tailed.

${ }^{*} p<.05 .{ }^{* *} p<.01 .{ }^{* * *} p<.001$.

The final two columns in Table 2 reveal that G1 divorce was not associated with G3 divorce. Duration of marriage (as reflected in duration and duration squared) was associated with divorce in the expected direction. That is, the odds of divorce increased during the early years of marriage but declined after that. G2 divorce was a significant predictor of G3 divorce. The $b$ coefficient for this variable represented an odds ratio of 2.23. In other words, G2 divorce appeared to increase the odds of G3 divorce by $123 \%$. Consistent with other studies, age at marriage was negatively related to divorce, with each year the people waited to marry being associated with a $13 \%$ decline in the odds of divorce.

Table 3 shows the results for G3 relationships with mothers, G3 relationships with fathers, and G3 psychological well-being. In Model 1, G1 divorce was associated with a decline of about one fifth of a standard deviation in G3 closeness to mothers. In Model 2, G3 closeness to mothers was negatively associated with G2 marital discord and G2 tension in parent-child relationships. These two variables, collectively, reduced the G1 $\rightarrow$ G3 coefficient by $43 \%$ and rendered it nonsignificant. These results suggest that G1 divorce weakens ties between G2 mothers and G3 offspring in adulthood by increasing interparental discord and tension between parents and children while children are growing up.

With respect to fathers, G1 divorce was associated with weaker G3 father-child relationships in Model 1, and the b coefficient reflected an effect size equivalent to almost one fourth
(.23) of a standard deviation. In Model 2, the quality of the G3 father-child relationship was associated negatively with G2 divorce, G2 marital discord, and G2 ratings of tension in parent-child relationships. With these variables in the model, the association between G1 divorce and G3 relations with fathers no longer was significant. Indeed, the G2 variables accounted for $96 \%$ of the original association, which indicates nearly perfect mediation. The two variables that played the strongest mediating role were G2 divorce and G2 discord. G2 divorce, on its own, reduced the b coefficient by $68 \%$, and G2 discord reduced the b coefficient by a further $28 \%$. Either of these variables was sufficient to render the association between G1 divorce and G3 relations with fathers nonsignificant.

Finally, G1 divorce did not predict G3 psychological well-being. In Model 2, however, G3 psychological well-being was negatively associated with G2 discord and G2 ratings of parentchild tension.

Table 4 presents the total estimated effects of G1 divorce, then partitions the total effect into direct and indirect components. Significance tests for indirect effects were based on bootstrapped samples with 500 replications (Arbuckle, 1997). Note that G1 divorce had a significant direct effect on G3 education, and a significant indirect effect on G3 education via the G2 variables in the model. With respect to marital discord and relations with parents, the significant effects of G1 divorce were entirely indirect. That is, G1 divorce appeared to influence these outcomes by disrupting family processes 
Table 4. Total, Direct, and Indirect Estimated Effects of G1 Divorce on G3 Outcomes.

\begin{tabular}{lccc}
\hline G3 Outcome & $\begin{array}{c}\text { Total } \\
\text { Effect }\end{array}$ & $\begin{array}{r}\text { Direct } \\
\text { Effect }\end{array}$ & $\begin{array}{c}\text { Indirect } \\
\text { Effect }\end{array}$ \\
\hline G3 Education & $-0.74^{* *}$ & $-0.54^{*}$ & $-0.20^{*}$ \\
G3 Marital discord & $0.35^{* *}$ & 0.21 & $0.14^{* *}$ \\
G3 Divorce & 0.09 & -0.06 & 0.15 \\
G3 Relations mother & $-0.21^{*}$ & -0.12 & $-0.09^{*}$ \\
G3 Relations father & $-0.23^{* *}$ & -0.01 & $-0.22^{* * *}$ \\
G3 Well-being & 0.02 & 0.10 & $-0.08^{*}$ \\
\hline
\end{tabular}

${ }^{*} p<.05 .{ }^{* *} p<.01 .{ }^{* * *} p<.001$.

in the middle generation. Table 4 yielded one unexpected finding. The total and direct effects of G1 divorce on G3 psychological wellbeing were positive but nonsignificant. The indirect effect of G1 divorce on G3 psychological well-being was significant, however, suggesting that G1 divorce indirectly affected this outcome through its effect on G2 variables. With the exception of G3 education, therefore, all of the estimated causal effects of G1 divorce were indirect. (Keep in mind that the term effect is used here in a statistical sense. We cannot prove causation with correlational data.)

\section{Gender differences}

A secondary goal of our study was to search for gender differences in the links between G1 divorce and G3 outcomes. We conducted a series of multigroup analyses, with the sample split into men and women. In one analysis, we allowed the parameter estimates between G1 and G3 variables to vary across genders. In a second analysis, we constrained the parameter estimates (one at a time) to be the same for men and women. The differences in chi-square values between these models were tested for significance. This procedure revealed that allowing model parameters to differ for men and women did not significantly improve the fit of the model to the data. Chi-square values (with one degree of freedom) were 1.92 for education, 1.81 for marital discord, 1.29 for divorce, 0.18 for the mother-child relationship, 1.03 for the father-child relationship, and 1.29 for psychological well-being (all $p>$.1). In other words, the links between G1 divorce and G3 outcomes were similar for men and women in our data.

\section{Changes in the intergenerational consequences of divorce}

To determine whether the estimated effects of divorce became weaker (or stronger) over time, we pooled the G2 and G3 data and incorporated decade of birth into the analysis, beginning with the 1920s (when the oldest G2 respondents were born) and ending with the 1970s (when the youngest G3 respondents were born). Three outcomes were available for this purpose: educational attainment, marital discord, and divorce.

Mean years of education rose across birth cohorts, ranging from 13.6 for individuals born in the 1920s to 14.4 for individuals born in the 1970s. Across the entire sample, parental divorce (controlling for parental education) was associated with a decline in education equivalent to .41 of a year $(p<.01)$. To test the interaction between parental divorce and birth cohort, we conducted two multigroup analyses. In one analysis, the association between parental divorce and offspring education was allowed to differ across cohorts, and in the second analysis, the association was constrained to be identical across cohorts. The difference in chi-square values between the unconstrained and constrained models was not significant $\left(\chi^{2}=7.48\right.$, $\mathrm{df}=5)$. In other words, a model that included interactions between parental divorce and birth cohort fit the data no better than did a model without interactions.

A comparable result was obtained for marital discord. Discord rose gradually across birth cohorts, with an average increase of .06 of a standard deviation for each decade $(p<.05)$. Across the entire sample, parental divorce was associated with an increase in discord equivalent to .4 of a standard deviation. Allowing the association between parental divorce and offspring's discord to vary across cohorts, however, did not improve the fit of the model $\left(X^{2}=\right.$ 7.51, $\mathrm{df}=5$ ).

Finally, an event history analysis revealed that annual odds of divorce rose consistently across birth cohorts, with an average increase of $4.5 \%$ for each decade $(p<.001)$. Across the full sample, parental divorce doubled the odds of divorce $(p<.001)$. Consistent with the other analyses, however, parental divorce did not interact with decade of birth in predicting offspring divorce. The difference in chi-square values for a model without interaction terms and a 
model with interaction terms (one for each decade minus 1) was not significant $\left(\chi^{2}=1.81\right.$, df $=5$ ). Overall, these results provide no support for the notion that the intergenerational effects of divorce changed over time.

\section{Discussion}

Few studies have documented the transmission of family problems across more than two generations. Given this gap in the research literature, the primary goals of our study were straightforward. We used data from a 20 -year longitudinal study to determine whether divorce in the grandparent generation had implications for well-being in the grandchild generation. Our analysis revealed that divorce between grandparents was associated with a variety of problematic outcomes for grandchildren, including lower educational attainment, greater marital discord, and poorer quality relationships with mothers and fathers. The associations between G1 divorce and G3 outcomes were not large in absolute terms, ranging from about one fifth to one third of a standard deviation. Nevertheless, these effect sizes were large enough to be nontrivial (Cohen, 1988). Moreover, given the length of time between G1 divorce and the assessment of G3 outcomes (over 40 years, on average), and given that fewer than $10 \%$ of G3 respondents had been born at the time that their grandparents divorced, the existence of these connections is remarkable. These findings suggest that parental divorce has consequences, not only for the children of these parents, but also for subsequent generations not yet born at the time that the divorce occurred. These results are consistent with the prior study by Caspi and Elder (1988) and with the general life course assumption that family members' lives are linked across multiple generations (Bengtson \& Allen, 1994; Elder, 1994).

Our second goal was to explain these G1 $\rightarrow$ G3 associations with reference to family process and socioeconomic variables in the parent (G2) generation. Our results indicated that characteristics of the parent generation can explain most of these associations. G1 divorce appeared to lower educational attainment, increase marital instability, increase marital discord, and increase tension between parents and children in the G2 generation. Problems in the middle generation, in turn, appeared to lower G3 education, increase G3 marital discord, and weaken G3 bonds with parents. Overall, these findings supported our mediation model: G1 variables appeared to influence G3 outcomes mainly by affecting characteristics of the middle generation.

The one exception involved G3 education. With all G2 variables in the model, the direct effects of G1 divorce on G3 education continued to be statistically significant. The absence of complete mediation suggests that our model was not correctly specified. That is, G1 divorce may have affected G2 family processes that we failed to measure and include in the statistical model. Although we included a measure of tension between G2 parents and their children, we did not include parenting measures related specifically to educational attainment. For example, we did not include a variable reflecting G2 parents' support for children's educational success.

To assess the possibility that our model was incorrectly specified, we returned to the G3 interviews and incorporated two additional items. One question asked respondents to rate the extent to which their parents had encouraged them to attend college. A second question asked respondents whether their parents had provided economic support for college attendance. Responses to both of these items were correlated significantly with G1 divorce. Specifically, G3 respondents reported less encouragement to attend college and less financial support for college if their grandparents had divorced. Moreover, responses to these two questions were significantly associated with G3 years of education in the expected direction. Adding these variables to the statistical model reduced the estimated effect of G1 divorce on G3 education by an additional $33 \%$ - that is, from .54 (Model 2, Table 2) to .36. Although the remaining b coefficient continued to be significant $(p=.048)$, it is likely that a more fully specified model would have reduced the direct effect of G1 divorce to a nonsignificant level.

Our study also addressed two supplementary goals. Because gender differences are discussed frequently in this literature, we used multigroup models to search for gender differences in our data. We found no evidence, however, that the consequences of G1 divorce differed for G3 men and women. Our study also tested the hypothesis that the intergenerational consequences of divorce have become weaker in recent decades, a hypothesis proposed by Amato and Keith (1991) and Wolfinger (1999). We 
tested this idea by including interaction terms between decade of birth and parental divorce. These analyses revealed no evidence to support this hypothesis. These null results are consistent with a study by Teachman (2002), who found no change in the association between parental divorce and offspring divorce in cohorts married between 1950 and 1984 in the National Survey of Family Growth.

\section{Genetic transmission or family environment?}

Although our results support a life course perspective, an alternative explanation holds that G1 $\rightarrow$ G2 $\rightarrow$ G3 linkages are due to genetically transmitted traits. Although we could not test this explanation directly, we were able to conduct a partial, indirect test. If divorce is transmitted across generations by genetic factors, then biological parents who were divorced prior to the marriage that produced the focal child should have transmitted this predisposition to their children, even if the second marriage did not end in divorce. In other words, children who grew up with continuously married (but previously divorced) parents should inherit traits that increase their risk of interpersonal problems, much like children with divorced parents. These associations should be especially strong if both parents (rather than one) were previously divorced. Using this procedure, Capaldi and Patterson (1991) found that children living with continuously married (but previously divorced) parents were at greater risk of certain problems than were children living with continuously married (never divorced) parents.

Following this strategy, we compared two groups of G3 respondents: 504 with continuously married (and never divorced) G2 parents, and 41 respondents with continuously married (but previously divorced) G2 parents. Of these 41 cases, 14 involved the father's prior divorce, 12 involved the mother's prior divorce, and 15 involved a prior divorce on the part of both parents. Associations between parents' history of divorce and G3 outcomes (in the absence of children's direct exposure to divorce) would provide indirect support for the genetic transmission hypothesis. However, the mean differences between these two groups of G3 respondents across all six outcomes in Tables 2 and 3 were not statistically significant. With only 41 cases, of course, the statistical power of these tests to detect significant differences in the population was modest. Nevertheless, five of the six differences between means were not in the direction predicted by the hypothesis (i.e., children with previously divorced parents reported fewer problematic outcomes). This general pattern did not change when we examined only those G3 respondents with two (rather than one) previously divorced parents. Although our findings provide little support for the assumption of a genetic link between parental divorce and offspring problems, future studies with genetically informed designs are required to provide clearer guidance on this point.

\section{Limitations and strengths of the study}

Like all studies, our study has several limitations. First, although we had information on G1 divorce and education, we did not have information on other G1 characteristics, such as marital discord or parent-child tension. For this reason, it is possible that other stressful features of G1 family life were the real culprits in initiating an intergenerational cycle of family problems. Because divorce, marital discord, and weak parent-child ties tend to cluster together in families, a more cautious interpretation of our findings is that family problems defined broadly (including divorce) have consequences that persist for generations. Moreover, although we focused on divorce, other family transitions-such as the death of a parent, parental cohabitation, and parental remarriage - can have intergenerational consequences. Incorporating these additional variables into the analysis, however, would have taken us beyond the original goals of our study.

Second, we did not obtain information directly from the G1 generation. Nevertheless, our G1 variables (divorce and education) are relatively objective, and hence less subject to memory bias than are other features of family life, such as perceptions of interparental discord and the quality of parent-child relationships. Third, our sample was necessarily selective because some G2 respondents dropped out of the study prior to 1992, and some G3 individuals declined to participate. Although we used the Heckman (1979) procedure to correct for attrition bias, this method is not foolproof and can lead to misleading conclusions under certain conditions (Stolzenberg \& Relles, 1997). 
Fourth, we obtained data from one G2 respondent and one G3 respondent per family. For some variables, such as divorce, this strategy is not problematic. But for other variables, such as marital discord, the views of spouses may differ substantially. Moreover, our measure of G2 tension in parent-child relationships was based on one parent's (rather than both parents') reports of tension with all of the children in the household (rather than the focal G3 child). We would have preferred both parents' reports about the focal G3 child, but these data were not available.

Finally, the G3 sample was young (with a median age of 32), and many either had not yet married or had married relatively recently. Because the risk of divorce increases after the first few years of marriage, many marriages that eventually will end in divorce were not captured in our analysis. For this reason, we may have underestimated the strength of the association between G1 divorce and G3 divorce.

Despite these limitations, our study has certain strengths. We used parents' reports of G2 characteristics and offspring's reports of G3 characteristics, thus avoiding the problems of same-source bias and common method variance. Our data were prospective, and hence in the correct causal order, with G1 and G2 variables measured between 1980 and 1992, and G3 variables measured between 1992 and 2000. Our study also included a variety of outcomes, ranging from education to marital discord to psychological well-being. The availability of these variables made it possible to cast a wide net in searching for linkages between grandparents' divorces and grandchildren's well-being.

\section{Conclusion}

Our study suggests that events in the lives of grandparents can have long-term implications for the lives of grandchildren. Grandparents' decisions to divorce predict less education, greater marital discord, and weaker ties with parents two generations later. To our knowledge, our study is the first to demonstrate significant associations between G1 divorce and G3 outcomes. These findings are particularly striking when we consider that the great majority of grandchildren were not yet born when these divorces occurred. Our study also shows how family problems can persist across generations, with divorce (and perhaps other family problems correlated with divorce) in one generation resulting in lower educational attainment and problematic family relationships in the second generation, and these outcomes in turn becoming the causes of similar problems in the third generation. Although our study cannot demonstrate causality, it suggests a surprising possibility: Parents who fight frequently or divorce may increase the risk of a variety of problems, not only for their children, but also for their children's children.

\section{Note}

This project was supported by the National Institute on Aging (grant R01 AG04146) and by the Population Research Institute (The Pennsylvania State University), with core support from the National Institute of Child Health and $\mathrm{Hu}$ man Development (grant 1-HD28263). Support also was received from an NICHD grant for Interdisciplinary Training in Demography (grant 5T32 HD07514) to the Population Research Institute and the Graduate Program in Demography at The Pennsylvania State University.

\section{References}

Allison, P. D. (1984). Event history analysis: Regression for longitudinal data. Beverly Hills, CA: Sage.

Allison, P. D. (2002). Missing data. Thousand Oaks, CA: Sage.

Amato, P. R. (2000). Consequences of divorce for adults and children. Journal of Marriage and the Family, 62, 1269-1287.

Amato, P. R., \& Booth, A. (1996). A prospective study of parental divorce and parent-child relationships. Journal of Marriage and the Family, 58, 356-365.

Amato, P. R., \& Booth, A. (1997). A generation at risk: Growing up in an era of family upheaval. Cambridge, MA: Harvard University Press.

Amato, P. R., \& Keith, B. (1991). Separation from a parent during childhood and adult socioeconomic attainment. Social Forces, 70, 187-206.

Amato, P. R., \& Sobolewski, J. M. (2001). The effects of divorce and marital discord on adult children's psychological well-being. American Sociological Review, 66, 900-921.

Arbuckle, J. L. (1997). Amos user's guide. Version 3.6. Chicago: SmallWaters. 
Bandura, A. (1973). Aggression: A social learning analysis. Englewood Cliffs, NJ: Prentice-Hall.

Bengtson, V. L., \& Allen, K. R. (1994). The life course perspective applied to families over time. In P. G. Boss, W. J. Doherty, R. Larossa, W. R. Schumm, \& S. K. Steinmetz (Eds.), Sourcebook of family theories and methods: A contextual approach (pp. 469-498). New York: Plenum.

Booth, A., Amato, P. R., \& Johnson, D. R. (2001). Marital instability over the life course: Methodology report for sixth wave. Lincoln: University of Nebraska Bureau of Sociological Research.

Brodzinsky, D., Hitt, J. C., \& Smith, D. (1993). Impact of parental separation and divorce on adopted and nonadopted children. American Journal of Orthopsychiatry, 63, 451-461.

Bumpass, L. L., Martin, T. C., \& Sweet, J. A. (1991). The impact of family background and early marital factors on marital disruption. Journal of Family Issues, 12, 22-42.

Capaldi, D. M., \& Patterson, G. R. (1991). The relation of parental transitions to boys' adjustment problems: I. A linear hypothesis, and II. Mothers at risk for transitions and unskilled parenting. Developmental Psychology, 27, 489-504.

Caspi, A., \& Elder, G. H. (1988). Emergent family patterns: The intergenerational construction of problem behavior and relationships. In R. A. Hinde \& J. Stevenson-Hinde (Eds.), Relationships within families (pp. 218-240). New York: Oxford University Press.

Cherlin, A. J., Chase-Lansdale, P. L., \& McRae, C. (1998). Effects of divorce on mental health throughout the life course. American Sociological Review, 63, 239-249.

Cohen, J. (1988). Statistical power analysis for the behavioral sciences (2nd ed.). Hillsdale, NJ: Erlbaum.

Davies, P. T., \& Cummings, E. M. (1994). Marital conflict and child adjustment: An emotional security hypothesis. Psychological Bulletin, 116, 387-411.

Doumas, D., Margolin, G., \& John, R. S. (1994). The intergenerational transmission of aggression across three generations. Journal of Family Violence, 9, 157-175.

Elder, G. H. (1994). Time, agency, and social change: Perspectives on the life course. Social Psychology Quarterly, 57, 5-15.

Gottman, J. M. (1994). What predicts divorce? Hillsdale, NJ: Erlbaum.
Hazan, C., \& Shaver, P. R. (1992). Broken attachments: Relationship loss from the perspective of attachment theory. In T. L. Orbuch (Ed.), Close relationship loss: Theoretical approaches (pp. 90-110). New York: Springer-Verlag.

Heckman, J. J. (1979). Sample selection bias as a specification error. Econometrics, 47, 153-161.

Hetherington, E. M., \& Clingempeel, W. G. (1992). Coping with marital transitions. Monographs of the Society for Research in Child Development, 57(2-3). Chicago: University of Chicago Press.

Jockin, V., McGue, M., \& Lykken, J. T. (1996). Personality and divorce: A genetic analysis. Journal of Personality and Social Psychology, 71, 288-299.

Kendler, K. S., Neale, M. C., Kessler, R. C., Heath, A. C., \& Eaves, L. J. (1992). Childhood parental loss and adult psychopathology in women. Archives of General Psychiatry, 49, 109-116.

Lamb, M. (1999). Noncustodial fathers and their impact on the children of divorce. In R. A. Thompson \& P. R. Amato (Eds.), The postdivorce family: Children, parenting, and society (pp. 105-126). Thousand Oaks, CA: Sage.

Leonard, K. E., \& Roberts, L. J. (1998). Marital aggression, quality, and stability in the first year of marriage: Findings from the Buffalo Newlywed Study. In T. N. Bradbury (Ed.), The developmental course of marital dysfunction (pp. 4473). New York: Cambridge University Press.

McGue, M., \& Lykken, D. T. (1992). Genetic influence on risk of divorce. Psychological Science, 3, 368-373.

McLanahan, S., \& Sandefur, G. (1994). Growing up in a single-parent family: What helps, what hurts. Cambridge, MA: Harvard University Press.

O'Leary, K. D., \& Cascardi, M. (1998). Physical aggression in marriage: A developmental analysis. In T. N. Bradbury (Ed.), The developmental course of marital dysfunction (pp. 343-374). New York: Cambridge University Press.

Raghunathan, T. E., Solenberger, P. W., \& Van Hoewyk, J. V. (2002). IVEware: Imputation and variance estimation software: User guide. Ann Arbor: Survey Methodology Program, Survey Research Center, Institute for Social Research, University of Michigan.

Ross, C. E., \& Mirowsky, J. (1999). Parental divorce, life-course disruption, and adult depression. Journal of Marriage and the Family, 61, 1034-1045. 
Rubin, D. B. 1987. Multiple imputation for nonresponse in surveys. New York: Wiley.

Stolzenberg, R. M., \& Relles, D. A. (1997). Tools for intuition about sample selection bias and its correction. American Sociological Review, 62, 494-507.

Tallman, I., Gray, L. N., Kullberg, V., \& Henderson, D. (1999). The intergenerational transmission of marital conflict: Testing a process model. Social Psychology Quarterly, 62, 219-239.

Teachman, J. D. (2002). Stability across cohorts in divorce risk factors. Demography, 39, 331-351.

Teachman, J. D., \& Paasch, K. M. (1994). Financial impact of divorce on children and the family. Future of Children, 4, 63-83.

Thompson, L., \& Walker, A. J. (1991). Gender in families: Women and men in marriage, work, and parenthood. In A. Booth (Ed.), Contemporary families: Looking forward, looking back (pp. 76-102). Minneapolis, MN: National Council on Family Relations.
Webster, P. S., Orbuch, T. L., \& House, J. S. (1995). Effects of childhood family background on adult marital quality and perceived stability. American Journal of Sociology, 101, 404-432.

Wolfinger, N. H. (1999). Trends in the intergenerational transmission of divorce. Demography, 33, 415-420.

Zill, N., Morrison, D. R., \& Coiro, M. J. (1993). Long-term effects of parental divorce on parent-child relationships, adjustment, and achievement in young adulthood. Journal of Family Psychology, 7, 91-103. 